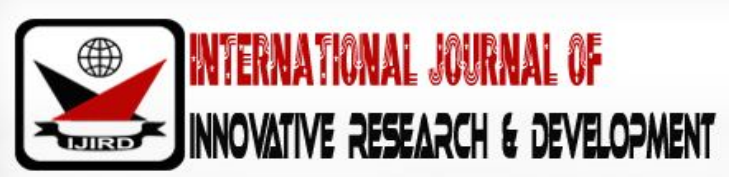

ISSN 2278 - 0211 (Online)

\section{Using Simulation as a Learning Strategy in Peri-Operative Nursing Education: Exploratory Descriptive Study}

\author{
Bishoy Awadalla \\ Assistant Lecturer, Cairo University, Egypt \\ Liliane Narouz \\ Lecturer, Cairo University, Egypt \\ Dr. José Amendoeira \\ Coordinator Professor, Nursing at Polytechnic Institute of Santarém, Portugal \\ Dr. Marianne Pitkäjärvi \\ Senior Lecturer, Helsinki Metropolia University of Applied Sciences, Finland
}

\begin{abstract}
:
Simulation has been shown to be an effective learning environment for students to learn and practice complex perioperative nursing as it provides experiential learning that can affects patient care, health, and safety. The aim of the study is to explore the effect of using simulation as a learning strategy in perioperative education on the nursing selfconfidence, technical skills (TSs) and non-technical skills (NTSs). A descriptive, exploratory design was used to investigate self-confidence, Technical Skills and Non-Technical Skills levels using simulation training scenarios. Sample: A purposive sample (44/158) of undergraduate nursing students who were conducting their perioperative nursing education in autumn 2015. The study was conducted at Metropolia's simulation laboratory at Helsinki Metropolia University of Applied Sciences, Finland. PostOperative Simulation Sheet (POSS) was used. Results shows that Nursing students were confident with intra/ postoperative simulation; For Intra and postoperative simulation Technical Skills and Non-Technical Skills they were occurred with a good level. Simulation as a learning strategy has been shown to be effective in providing students with a safe environment for learning perioperative patient care and has shown potential in improving student's learning outcomes such self-confidence, TSs and NTSs.
\end{abstract}

Keywords: Simulation, self-confidence, technical skills (TSs), non-technical skills (NTSs), perioperative nursing

\section{Introduction}

Simulation is an important tool that can be used in the nursing curriculum to increase experiences in nursing practice. (Durham, \& Alden, 2008). It involves active student participation, and help to reinforces the development of assessment skills, psychomotor activity, critical thinking, problem solving, decision making, and collaboration with others (LaMartina \& WardSmith 2014), it provides experiential learning that can affects patient care, health, and safety. (Rothgeb, 2008).

Human patient simulation is a relatively new teaching strategy that allows learners to develop, refine, and apply knowledge and skills in a realistic clinical situation as they participate in interactive learning experiences designed to meet their educational needs has revolutionized the way of teaching in healthcare settings. (Gaba, 2004; Maran \& Glavin, 2003).

Perioperative contexts are interdisciplinary, multispecialty, and involve patients who are at risk of instability during this acute phase of care; it also involves the interaction of a multi-disciplinary team of healthcare professionals, (Petrovic et al., 2012).

Simulation environments reduce and eliminate anxieties produced with providing care for real patients. (Walsh, 2010). The skills requirements which can be enhanced with the use of simulation include (situation awareness, decision-making, communication, team working and leadership skills) all of these share a common thread in that they require active listening and collaboration besides possession of the basic knowledge and skills. (Gupta, Peckler, \& Schoken, 2008). 


\section{Methodology}

\subsection{Aim of the Study}

To explore the effect of using simulation as a learning strategy in perioperative education on the nursing self-confidence, technical skills (TSs) and non-technical skills (NTSs).

\subsection{Objectives of the Study}

- To explore nursing students' self-confidence.

- To explore nursing students' technical skills (TSs) and non-technical skills (NTSs)

\subsection{Research Questions}

How does the use of perioperative simulation training scenarios affect self-confidence, TSs and NTSs among nursing students who are conducting their perioperative education at Metropolia's simulation laboratory at Helsinki Metropolia University of Applied Sciences, Finland?

\subsection{Significance of Study}

Perioperative environment is considered one of the most sophisticated and challenging environment in acute care contexts where communication errors and mistakes could have serious and fatal implications. In fact, the most frequently reported cause of sentinel events within U.S. hospitals is poor NTSs (Street et al., 2011). Specifically, the risk for adverse events occurs more often for surgical patients than in any other clinical specialty (Amato-Vealey, Barba, \& Vealey, 2008).

The study offers the opportunity for nursing students to practice skills, techniques, communication, problem solving and critical thinking in a safe environment; it offers innovative ways of teaching students about real situation in a controlled environment (Jeffries, 2009; Webster, 2009).

\subsection{Sampling}

A purposive sample (44/158) divided into 4 groups $(11,11,14$, and 8) undergraduate nursing students who were conducting their perioperative nursing education in autumn 2015, voluntarily accepting to participate in this research after a written consent, being familiar with the simulation lab at Helsinki Metropolia University of Applied Sciences, Finland.

\subsection{Research Design}

A descriptive, exploratory design was used to investigate self-confidence, TSs and NTSs levels using simulation training scenarios among nursing students at Helsinki Metropolia University of Applied Sciences, Finland.

\subsection{Instruments}

The POSS (See Appendix A) was developed by the researcher after extensive literature review with a collaboration with facilitators and then submitted to a panel of three reviewers and experts in critical care and perioperative nursing. Revision of the tool was made based on the feedback from the reviewers and before conducting the study. The POSS consisted of two main sections; the first section was used to collect self-reported data on socio-demographic variables related to the observed subjects as age, gender, educational background, enrolled program, attendance time in the simulation laboratory, hours spent in the simulation laboratory, healthcare working experience, student's role played during simulation in both intraoperative and postoperative simulation training scenarios.

The second section in POSS is divided into three parts; the first part is students' self-confidence tool in perioperative simulation with eight items adapted from (NLN, 2004) (See Appendix A \& Appendix D for NLN permission letter), The second part was a perioperative TSs checklists consisted of two checklists the first one for intraoperative TSs using four main objectives the first was to achieve a successful negotiation regarding the roles (one item), the second objective was to explain the process and progress of spinal anesthesia (six items), the third objective was to know how to instruct the patient to a correct position (eight items), the fourth objective was to perform the skin disinfection to the spinal anesthesia (seven items) the second checklist for postoperative TSs using ABCDE assessment model: A for Airway with (two items), B for Breathing with (two items), C for circulation with (five items), D for disability with (four items), and E for exposure with (four items). The third part was a perioperative NTSs checklist (was used for intraoperative and postoperative simulation training scenarios) consisted of two categories: first category assessed two cognitive skills (situation awareness and decision-making), the second category assessed two social skills (communication/ team-working and leadership) each sub category contains three sub items were evaluated by the researcher using correct mark for correct done action (equal one) and incorrect mark for incorrect or not done action (equal zero) (Briggs et al., 2015; Mullen \& Byrd, 2013; Gillon et al., 2012; Carne, Kennedy, \& Gray, 2011; St. Pierre, Hofinger, Buerschaper, \& Simon, 2011; Reader, Flin, Lauche, \& Cuthbertson, 2006; Fletcher et al., 2003).

\subsection{Procedure}

The researcher used simulation training scenarios at simulation lab at Helsinki Metropolia University of Applied Sciences, Finland. which involved 44 nursing students who were conducting their perioperative curriculum. Students were 
divided into four groups for two days (two groups per day) going through perioperative simulation practice (one for intraoperative simulation skills occurred in the $3^{\text {rd }}$ floor simulation lab and the second for postoperative simulation skills occurred in the $5^{\text {th }}$ floor simulation lab).

In the intraoperative simulation practice; three students from each group shared to play the role of a nurse, anesthesiologist and a standardized patient. The standardized patient was asked in the briefing session to act as a 55 years old cardiac patient who was planned to undergo spinal anaesthesia for open inguinal hernia repair. Observing students were asked by the perioperative educator to take during the simulation training scenario event to be used later on in the debriefing session.

In the postoperative simulation practice: three students shared to play the role of a nurse, a doctor and a standardized patient who act as semiconscious patient in PACU on a simple mask oxygen with $99 \%$ O2 saturation, the patient was connected to haemodynamic monitor and pulse oximetry, the patient was also connected to one drain for blood drainage. The pain scale was 7 over 10 .

In both intra/ postoperative simulation scenarios with the all four groups; POSS, the second and the third parts in the second section, was used by the investigator assisted by video-taping and with the help of the co-supervisor to investigate students' TSs and NTSs levels. After the debriefing session, all nursing students were asked to fill in the self-confidence tool; POSS, first part in the second section. 2004)

The rating scale for self-confidence, TSs and NTSs levels were as the following: adapted from (NLN, 2004; Fletcher,

- $\quad$ 1-Less than (33.3\%) was considered poor level: (Not confident)

- (TSs and NTs Simulation performance endangered or potentially endangered patient safety, serious remediation was required).

- 2-From (33.3\%) to (66.6\%) was considered acceptable level: (Neutral)

- (TSs and NTs, simulation performance was of a satisfactory standard but some improvements were needed).

- 3-More than $66.6 \%$ was considered good level: (Confident)

- (TSs and NTs Simulation performance was for a consistently high standard, enhancing patient safety; it could be used as a positive example for others).

\subsection{Data Analysis}

The data was scored, tabulated and analyzed by using Statistical Package for the Social Sciences (SPSS-version 21) descriptive statistics were utilized as standard deviation, frequency, mean and percentage (Woolf, Keating, Burge, \& Michael 2004).

\subsection{Ethical Consideration}

A written formal research permit and a Formal permission letter from NLN (2004) was obtained in November, 2015; the tool was modified to collect data related to students' self-confidence. Subjects' names were not written for the purpose of anonymity and confidentiality. Subjects were free to withdraw from the study at any time. They were assured that the results of the study would not be used for any performance evaluation.

\section{Results}

Table (1) shows that nursing students' mean age was 25.73 \pm 6.92 years old; $\quad(95 \%) \quad$ were females. high school educational background had the highest frequency (64\%); Student nurses who enrolled nursing program were (52\%) followed by public health (36\%) while those who are enrolled in midwifery and paramedics programs (7\%) and (5\%) respectively. The students play different roles in the simulation scenarios (18\%) played the role of the nurse; $(9 \%)$, patients and $(73 \%)$ observers while during postoperative simulation training scenario $(20 \%)$ played the role of the, nurses; $(14 \%)$, patients and $(66 \%)$. 


\begin{tabular}{|c|c|c|c|}
\hline Demographic Variables & $\mathrm{n}=\mathbf{4 4}$ & $(\%)$ & Mean \pm SD \\
\hline $\begin{array}{c}\text { Age } \\
\text { Less than } 25 \text { years old } \\
\text { From } 25 \text { to } 30 \text { years old } \\
\text { More than } 30 \text { years old }\end{array}$ & $\begin{array}{l}27 \\
9 \\
8\end{array}$ & $\begin{array}{l}61 \\
21 \\
18\end{array}$ & $25.73 \pm 6.92$ \\
\hline $\begin{array}{c}\text { Gender } \\
\text { Male } \\
\text { Female }\end{array}$ & $\begin{array}{c}2 \\
42\end{array}$ & $\begin{array}{c}5 \\
95\end{array}$ & \\
\hline $\begin{array}{c}\text { Educational background } \\
\text { Vocational } \\
\text { High school } \\
\text { University degree }\end{array}$ & $\begin{array}{c}8 \\
28 \\
8\end{array}$ & $\begin{array}{l}18 \\
64 \\
18\end{array}$ & \\
\hline $\begin{array}{c}\text { Enrolled program } \\
\text { Nursing } \\
\text { Paramedics } \\
\text { Midwifery } \\
\text { Public health }\end{array}$ & $\begin{array}{c}23 \\
2 \\
3 \\
16\end{array}$ & $\begin{array}{c}52 \\
5 \\
7 \\
36\end{array}$ & \\
\hline $\begin{array}{c}\text { Attendance time in the simulation laboratory } \\
\text { Less than } 4 \text { times } \\
4 \text { times and more }\end{array}$ & $\begin{array}{l}29 \\
15\end{array}$ & $\begin{array}{l}66 \\
34\end{array}$ & $3.61+2.67$ \\
\hline $\begin{array}{c}\text { Hours spent in the simulation laboratory } \\
\text { Less than } 6 \text { hours } \\
\text { From } 6-10 \text { hours } \\
\text { More than } 10 \text { hours }\end{array}$ & $\begin{array}{l}14 \\
19 \\
11\end{array}$ & $\begin{array}{l}32 \\
43 \\
25\end{array}$ & $8.95 \pm 6.83$ \\
\hline $\begin{array}{c}\text { Health care working experience } \\
\text { Less than one year } \\
\text { One year and more }\end{array}$ & $\begin{array}{l}33 \\
11\end{array}$ & $\begin{array}{l}75 \\
25\end{array}$ & $1.00 \pm 2.13$ \\
\hline $\begin{array}{c}\text { Student's role in intraoperative simulation training } \\
\text { scenario } \\
\text { Nurse } \\
\text { Patient } \\
\text { Observer }\end{array}$ & $\begin{array}{l}8 \\
4 \\
32\end{array}$ & $\begin{array}{c}18 \\
9 \\
73\end{array}$ & \\
\hline $\begin{array}{c}\text { Student's role in postoperative simulation training } \\
\text { scenario } \\
\text { Nurse } \\
\text { Patient } \\
\text { Observer }\end{array}$ & $\begin{array}{c}9 \\
6 \\
29\end{array}$ & $\begin{array}{l}20 \\
14 \\
66\end{array}$ & \\
\hline
\end{tabular}

Table 1: Frequency, and Percentage Distribution of Socio-Demographic Variables Related to Nursing Students or Observed Subjects ( $\mathrm{N}=44)$

Regarding the level of self-confidence, Table (2), shows that the majority (95.5\%) of nursing students' answers were (confident) ranging from (not confident, neutral, or confident) in intra and postoperative simulation training scenarios. 


\begin{tabular}{|c|c|c|c|c|c|c|}
\hline \multirow[t]{3}{*}{ Demographic Variables } & \multicolumn{6}{|c|}{$\begin{array}{l}\text { Self-Confidence Frequency } \\
\text { Self-Confidence }\end{array}$} \\
\hline & \multicolumn{3}{|c|}{ Intraoperative simulation } & \multicolumn{3}{|c|}{ Postoperative simulation } \\
\hline & $\begin{array}{c}\text { Not } \\
\text { Confident }\end{array}$ & Neutral & Confident & $\begin{array}{l}\text { Not } \\
\text { Confident }\end{array}$ & Neutral & Confident \\
\hline Age & & & & & & \\
\hline Less than 25 years old & 0 & 1 & 26 & 0 & 1 & 26 \\
\hline From $25-30$ years old & 0 & 0 & 9 & 0 & 1 & 8 \\
\hline More than 30 years old & 0 & 0 & 8 & 0 & 0 & 8 \\
\hline Gender & & & & & & \\
\hline Male & 0 & 0 & 2 & 0 & 1 & 1 \\
\hline Female & 0 & 1 & 41 & 0 & 1 & 41 \\
\hline Educational background & & & & & & \\
\hline Vocational & 0 & 0 & 8 & 0 & 0 & 8 \\
\hline High school & 0 & 1 & 27 & 0 & 1 & 27 \\
\hline University degree & 0 & 0 & 8 & 0 & 1 & 7 \\
\hline Enrolled program & & & & & & \\
\hline Nursing & 0 & 0 & 23 & 0 & 2 & 21 \\
\hline Paramedics & 0 & 0 & 2 & 0 & 0 & 2 \\
\hline Midwifery & 0 & 1 & 2 & 0 & 0 & 3 \\
\hline Public health & 0 & 0 & 16 & 0 & 0 & 16 \\
\hline Attendance time in the simulation laboratory & & & & & & \\
\hline Less than 4 times & 0 & 0 & 29 & 0 & 2 & 27 \\
\hline 4 times and more & 0 & 1 & 14 & 0 & 0 & 15 \\
\hline Hours spent in the simulation laboratory & & & & & & \\
\hline Less than 6 hours & 0 & 0 & 14 & 0 & 0 & 14 \\
\hline From 6-10 hours & 0 & 1 & 18 & 0 & 2 & 17 \\
\hline More than 10 hours & 0 & 0 & 11 & 0 & 0 & 11 \\
\hline Health care working experience & & & & & & \\
\hline Less than one year & 0 & 0 & 33 & 0 & 1 & 32 \\
\hline One year and more & 0 & 1 & 10 & 0 & 1 & 10 \\
\hline $\begin{array}{l}\text { Student's role in intraoperative simulation } \\
\text { training scenario }\end{array}$ & & & & & & \\
\hline Nurse & 0 & 0 & 8 & 0 & 1 & 7 \\
\hline Patient & 0 & 0 & 4 & 0 & 0 & 4 \\
\hline Observer & 0 & 1 & 31 & 0 & 1 & 31 \\
\hline $\begin{array}{c}\text { Student's role in postoperative simulation } \\
\text { training scenario }\end{array}$ & & & & & & \\
\hline Nurse & 0 & 0 & & 0 & 0 & \\
\hline Patient & 0 & 0 & 6 & 0 & 0 & 6 \\
\hline Observer & 0 & 1 & 28 & 0 & 2 & 27 \\
\hline
\end{tabular}

Table 2: Frequency Distribution of Students' Self-Confidence in Relation to Socio-Demographic Variables in Perioperative Simulation $(\mathrm{N}=44)$

Table (3) illustrates that the about two third (67\%) of the nursing students had an overall satisfactory level of performance in the intra-operative TSs.

\begin{tabular}{|c|c|}
\hline Objectives & Total \\
\hline 1Negotiation & $1 / 4(25 \%)$ \\
\hline 2.Process explanation & $18 / 24(75 \%)$ \\
\hline 3 Instruct patient. for proper position & $19 / 32(59 \%)$ \\
\hline 4.Skin disinfection & $21 / 28(75 \%)$ \\
\hline Total & $59 / 88(67 \%)$ \\
\hline
\end{tabular}

Table 3: Frequency and Percentage Distribution of TSS Data Related to Intraoperative Simulation $(\mathrm{N}=88)$

* Indicates the Total Number of Intraoperative TSS 
Table (4) shows that, the total overall performance of postoperative TSs is (79\%) which is considered satisfactory performance level. The highest scores were in both airway and breathing management (100\%).

\begin{tabular}{|c|c|}
\hline ABCDE Approach & Total \\
\hline 1.Airway & $8 / 8(100 \%)$ \\
\hline 2.Breathing & $8 / 8(100 \%)$ \\
\hline 3.Circulation & $19 / 20(95 \%)$ \\
\hline 4.Disability & $13 / 16(81 \%)$ \\
\hline 5.Exposure & $13 / 16(81 \%)$ \\
\hline Total & $54 / 68(79 \%)$ \\
\hline
\end{tabular}

Table 4: Frequency and Percentage Distribution of TSS Data Related to Postoperative Simulation $(\mathrm{N}=68)^{*}$

* Indicates the Total Number of Postoperative TSS

Table (5) indicates that the total overall performance of both intra and post-operative NTSs is (92\%) which is considered a good performance level.

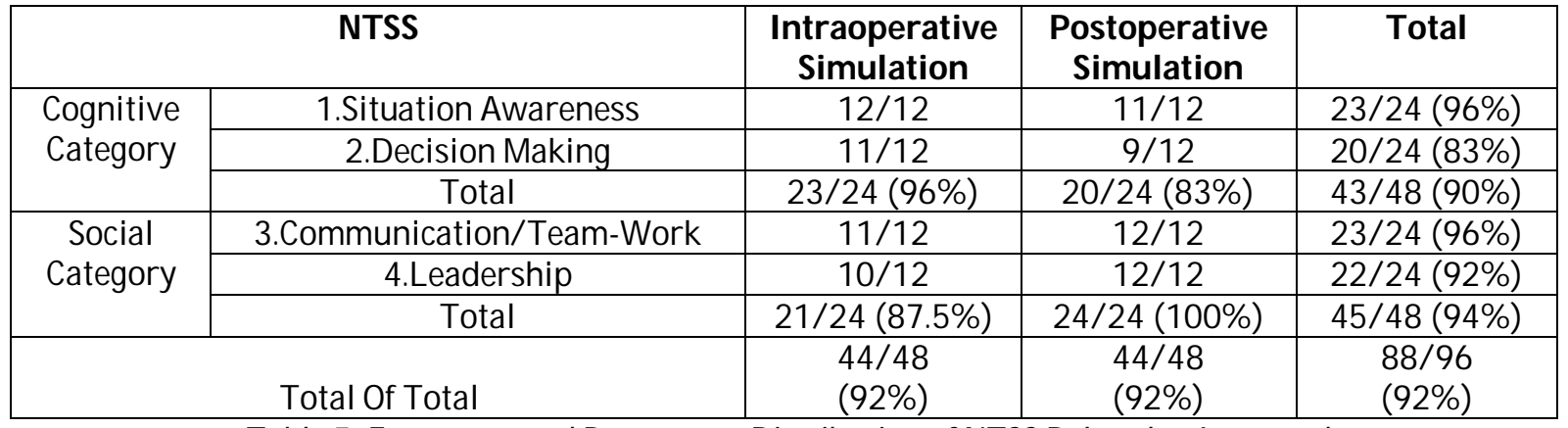

Table 5: Frequency and Percentage Distribution of NTSS Related to Intra and Postoperative Simulation ( $\mathrm{N}=96)^{*}$

* Indicates the Total Number of Intra and Postoperative NTSS

\section{Discussion}

A systematic review based on current available literature on simulation and nursing education indicated that simulation is useful in creating a learning environment that contributes to self-confidence, TSs and NTSs (Norman, 2012). In one study conducted by Foot (2007) supporting the current study result in a manner that nursing students can develop new TSs and NTSs through repeated experience with simulation, allowing repeated exposure to both common and rare clinical scenarios' in addition that Conducting simulation in a team context allows the opportunity for team building and development of interpersonal skills.

Another study conducted by Gillon, et al. (2012) supporting the current study in recognizing the importance of NTSs in education and training in acute environments as simulation has been shown to improve trainee self-confidence and performance when faced with a similar situation again and is found to be both beneficial and enjoyable by participants. Conducting simulation in a team context allows the opportunity for team building and development of interpersonal skills

\section{References}

i. Amato-Vealey, E., Barba, M. P., \& Vealey, R. J. (2008). Hand-off communication: A requisite for perioperative patient safety. AORNJournal, 88(5), 763-774.

ii. Briggs, A., Raja, A. S., Joyce, M. F., Yule S. J., Jiang, W, Lipsitz, S. R., and Havens, J. M. The Role of Nontechnical Skills in Simulated Trauma Resuscitation. (2015) J Surg Educ.; 72(4):732-9. doi: 10.1016/ j.jsurg.2015.01.020.

iii. Carne, B., Kennedy, M., \& Gray, T. (2011). Review article: Crisis resource management in emergency medicine.EMA.,24(1), 7-13emm9. DOI: 10.1111/j.1742-6723.2011.01495.

iv. Derry, S., Pea, R., Barron, B., Engle, R., Erickson, F., Goldman, R., Hall, R., Koschmann, T., Lemke, J., Sherin, M., \& Sherin B. (2010). Conducting Video Research in the Learning Sciences: Guidance on Selection, Analysis, Technology, and Ethics. Journal of the Learning Sciences, 19 (PP. 3-53).

v. Durham C. F. \& Alden K. R. (2008). Enhancing Patient Safety in Nursing Education Through Patient Simulation. Patient Safety and Quality: An Evidence-Based Handbook for Nurses. Agency for Healthcare Research and Quality. Retrieved @ https:/ / www.ncbi.nlm.nih.gov/ books/ NBK2628/

vi. Fletcher G, Flin R, McGeorgeP.Glavin, R., Maran, N., \& Patey, R. (2003). Anaesthetists' non-technical skills (ANTS): evaluation of a behavioural marking system. Br J Anaesth, 90(5), 580-8. 
vii. Foot C. (2007). Simulation for team crisis management training in critical care medicine - where have we been, where are we now and where are we going? Aust Anaes: 87-93.

viii. Gaba, D. M., (2004). The future vision of simulation in health care. Qual Saf Health Care;13(1):12-20.

ix. Gillon, S. Radford, S., Chalwin, R., DeVita, M., Endacott, R. and Jones, D. (2012). Crisis resource management, simulation training and the medical emergency team. Crit Care Resusc 14 (3), 227-235.

x. Gupta, A., Peckler, B., and Schoken, D. (2008). Introduction of hi-fidelity simulation techniques as an ideal teaching tool for upcoming emergency medicine and trauma residency programs in India.J Emerg Trauma Shock.;1:15-8

xi. Halstead, J. A. (2009). Evidence-based teaching and clinical simulation. Clinical Simulation in Nursing Education, 2(1), 5-8.

xii. Jeffries, P. R. (2009). GUEST Editorial: Dreams for the Future for Clinical Simulation. Nursing Education Perspectives (30)2, 71-71. doi: http:/ / dx.doi.org/ 10.1043/ 1536-5026-030.002.0071.

xiii. LaMartina, K\& Ward-Smith, P. (2014). Developing critical thinking skills in undergraduate nursing students: The potential for strategic management simulations. Journal of Nursing Education and Practice 4 (9) retrieved @ http:/ / www.sciedu.ca/ journal/ index.php/ jnep/ article/ viewFile/ 4872/ 3064

xiv. Maran, N., and Glavin, R. (2003). Low- to high-fidelity simulation--a continuum of medical education?. Medical Education, 37: 22-28.

xv. National League for Nursing (2004). Retrieved December 17, 2015 available at: http:// www.nln.org/ professionaldevelopment-programs/ research/ tools-and-instruments/ descriptions-of-available-instruments

xvi. Norman, J. (2012). Systematic Review of the Literature on Simulation in Nursing Education. ABNF Journal, 23(2), 2428.

xvii. Petrovic, M. A., Aboumatar, H., Baumgartner, W. A., Ulatowski, J. A., Moyer, J., Chang, T. Y., Camp, M. S., Kowalski, J., Senger, C. M., and Martinez, E. A. (2012). Pilot implementation of a perioperative protocol to guide operating room-tointensive care unit patient handoffs. J CardiothoracVascAnesth, 26(1), 11-16 doi: 10.1053/j.jvca.2011.07.009.

xviii. Reader, T., Flin, R., Lauche, K., Cuthbertson, B. H. (2006).Non-technical skills in the intensive care unit. Br J Anaesth, 96(5): 551-559.

xix. Rothgeb, M.K. (2008) Creating a nursing simulation laboratory: a literature review. Journal of Nursing Education. Nov;47(11):489-94.

xx. St. Pierre, M., Hofinger, G., Buerschaper, C., \& Simon, R., (2011). Crisis management in Acute Care setting: Human factors, team psychology, and patient safety in a high stakes environment ( $2^{\text {nd }}$ ed.). Heidelberg Dordrecht London New York: Springer publisher

xxi. Street, M., Eustace, P., Livingston, P., M., Craike, M., J., Kent, B., \& Patterson, D. (2011). Communication at the bedside to enhance patient care: A survey of nurses' experience and perspective of handover. International Journal of Nursing Practice, 17(2), 133-140.

xxii. Thim, T., Krarup, N. H., Grove, E. L., Rohd, C. V., Lofgren, B. (2012). Initial assessment and treatment with the Airway, Breathing, Circulation, Disability, Exposure (ABCDE) approach. Int J Gen Med. 5: 117-121. doi: 10.2147/ IJGM.S28478.

xxiii. Walsh, M. (2010). Using a simulated learning environment. Emergency Nurse, 18, 12-16.

xxiv. Webster, M. R. (2009). An innovative faculty toolkit simulation success. Nurse Educator, 34, 148-149.

xxv. Woolf, P., Keating, A., Burge C., and Michael, Y. (2004). Statistics and Probability Primer for Computational Biologists". Massachusetts Institute of Technology, BE 490/ 